\title{
The Current State and Future Perspectives of the Research Information Infrastructure in Croatia
}

Bojan Macan

Ruđer Bošković Institute

Zagreb, Croatia

Jelka Petrak

School of Medicine

University of Zagreb, Croatia bojan.macan@irb.hr

jelka.petrak@mef.hr

\begin{abstract}
The purpose of this paper is to analyze the existing Croatian research information infrastructure and to outline a new model of the Croatian Current Research Information System (CroRIS), required for the systematical monitoring and evaluation of the research processes and output of the Croatian public research and higher education institutions, as well as for the increasing of their international visibility. Based on the results of the analysis of the existing research information infrastructure in Croatia, the general outline of the new CERIF-based CroRIS model is proposed. The analysis of the existing research information infrastructure showed that there are some functional parts which could be reused and/or used as a basis for the implementation of the proposed CroRIS model. The proposed model represents a concept which would allow a quality decision and science-policy making in Croatia.

Keywords: Research information infrastructure, Current research information system, CRIS, Common European Research Information Format, CERIF, Croatian research information system, CroRIS, research evaluation
\end{abstract}

\section{Introduction}

High quality data about research activities and processes, so called research information (RI), are of strategic relevance and vital importance for both, science communication and research governance and policy [1]. A research information system (RIS) or current research information system (CRIS) is recording, storing and managing data about research activities of a community for which it has been implemented. CRISs usually contain information about research institutions, researchers and other persons involved in conducting research, projects, grants and funding, results (publications and patents), scientific equipment and events, but may also contain information about other aspects of scientific activity. CRIS systems integrate already registered and existing information helping to simplify and harmonize research management processes and secure the transparency of the 
administrative decision-making processes. Besides, CRISs stimulate scientific excellence, making national research performance visible and expanding scientific and research collaboration at international and interdisciplinary levels [2]. It may also maximize cost efficiency and fairness of money distribution [3].

These systems can be implemented on an institutional, multi-institutional or a national level. Biesbendar et al. noted that there are different approaches towards the institutional management, processing and dissemination of research information and research data in different national science systems [4]. Transparent science and innovation policy based on the research performance indicators are especially important for the research communities in the science-periphery countries [5]. These communities strongly depend on the public finance resources. The transparency in money distribution as well as in setting research priorities and mapping of scientific excellence are therefore critical in the building and growth of the research activities.

The data stored in CRIS's can be used for the evaluation purposes and/or datadriven decision making [6]-[9] provided that these data are complete, reliable, wellstructured and organized. Therefore, the system should comply with the guidance on managing records prescribed by the ISO 15489-1:2016 standard [10].

The use of appropriate metadata formats is also very important. MARC21 format, Metadata Object Description Schema (MODS) or Dublin Core (DC) are usually used for publications description [11], [12], while the Common European Research Information Format (CERIF) is a standard research information data exchange format. CERIF is recommended by the European Union to its member states in order to achieve interoperability between their information systems gathering data about research and technological development at national level [13] and to achieve maximum competitiveness of Europe at all levels of research activity [14]. In 2000 the European Commission (EC) handed over care and custody of CERIF to euroCRIS (www.eurocris.org) a not-for-profit organization dedicated to the promotion of Current Research Information Systems (CRISs) [15]. A CRIS can be implemented using a subset or superset of the full CERIF model for projects, persons, organizations, publications, patents, products, services and facilities (equipment in particular) with role-based, temporally-bound relationships [16]. However, it is very demanding for a CRIS system to be CERIF-based, especially on a national level, so some national CRIS systems are CERIF-compliant, and others are not [1], [17]. Very often there's a need for adding value to CRISs by enriching its metadata beyond CERIF model and/or developing different tools for analyzing data. In these cases the customization of CERIF is needed [2], [18], [19]. Besides metadata formats, the use of appropriate and well-structured controlled vocabularies is necessary for enabling certain functionalities.

Some of the most important added values to the CRIS systems are the linking of publication records to their full-texts available in open access (e.g. in the institutional repositories or the OpenAIRE infrastructure) and to various bibliometric indicators [18], [20]. 


\section{Current state of Croatian research information infrastructure}

Croatia is the newest European Union member state and its investment in research and development (R\&D) in 2016 reached $0.84 \%$ of its GDP. The majority of R\&D expenditure is spent in business sector $(45 \%)$, while $22 \%$ is spent in government sector and $33 \%$ in higher education (HE) sector [21].

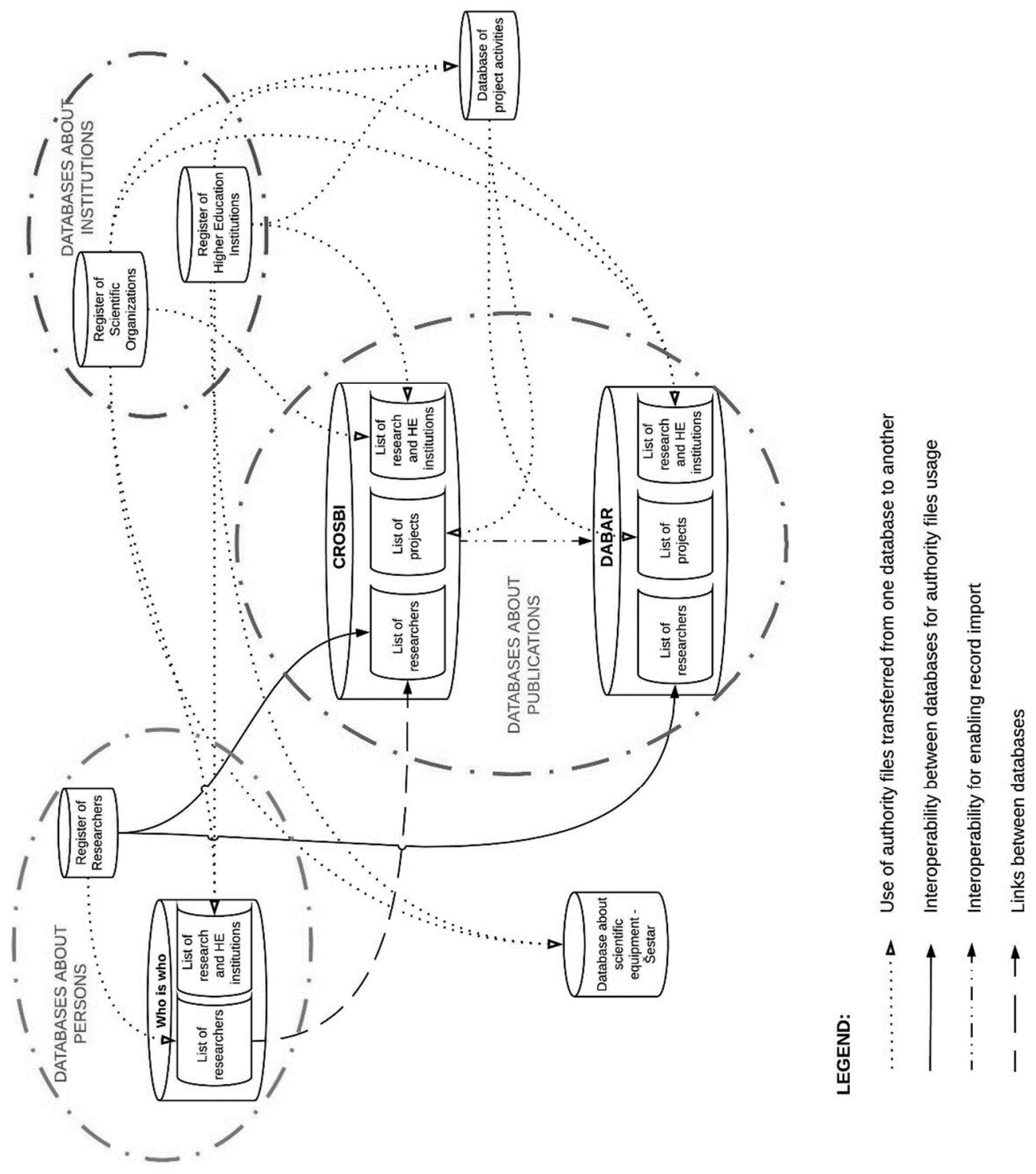

Figure 1. The existing parts of the research information infrastructure in Croatia and their interoperability between them 
There are currently 182 legal entities with a registered scientific activity, and they all are registered in the national Register of Scientific Organizations and eligible for public funding. The most numerous are the higher education institutes (HEI) -10 universities (8 public and 2 private), 72 constituent units of public universities (faculties, academies and university departments), 4 colleges ( 2 public and 2 private) and 4 public polytechnics. Besides, there are also 25 public research institutes and 70 other public institutions which have a research unit within their organizational structure (some museums, healthcare institutions, libraries etc.) ${ }^{1}$.

Croatia employs different research funding instruments and modalities. The most important are the ones provided by the Ministry of Science and Education of the Republic of Croatia (MSE) and the Croatian Science Foundation (CSF). As an illustration, approx. $20 \%$ of all papers with at least one Croatian affiliation which were published in the period 2012-2017 and indexed by the Web of Science Core Collection, name one of these two funding agencies ${ }^{2}$. The MSE gives direct financial allocations to public universities and public research institutes via multiyear performance based contracts, to their autonomous disposal. CSF provides support to scientific, higher education and technological programs and projects, and helps the realization of scientific programs of special interest. The coordination process and reporting regime on all of these activities require a research information infrastructure which could provide reliable data on institutions' research activity. These data are also important for the processes of reaccreditation of HEIs and research institutions which is periodically carried out by the Croatian Agency for Science and Higher Education (ASHE), as well as for the processes of scientific promotions of individuals.

So far, Croatia has not implemented CERIF-based CRIS system on a national (or institutional) level. However, some parts of the research information infrastructure on the national level already exist (Figure 1). This paper aims to overview and analyze these existing parts and their potential functionality in the new model of the Croatian Current Research Information System (CroRIS).

\subsection{Databases about institutions}

The Ministry of Science and Education of the Republic of Croatia (MSE) is maintaining two official registers about Croatian public and private institutions performing scientific activity and/or higher education studies. The Register of Scientific Organizations collects basic information about all Croatian public and private organizations which are licensed for research activities in Croatia. The Register of Higher Education Institutions collects similar data about all Croatian public and private institutions offering higher education. Higher education institutions can be registered in both registers. Both registers are enforced by the national

\footnotetext{
${ }^{1}$ Source of data: URL: https://www.azvo.hr/en/science/scientific-organisations (accessed 9 July 2018)

${ }^{2}$ Source of data: Web of Science Core Collection (URL: http://www.isiknowledge.com/WOS) (accessed 9 November 2018)
} 
legislation [22], [23]. All data are collected via paper forms ${ }^{3}$ which have to be sent to the MSE. Registries are not publicly available, except the basic lists of registered entities.

These registers could potentially become the components of the future CRIS system, and their integration into one database would partly satisfy the need for unique identification of the Croatian HE and research institutions. However, the database about institutions should also keep structured information about their subdivisions, currently missing in the registers. It is necessary to enable analysis and reports on a departmental level. The procedures for data gathering and update as well as administration should also be improved.

\subsection{Databases about persons}

Croatia currently has two databases about researchers, one is an official register maintained by the MSE and enforced by the national legislation (Register of the Researchers), and another is a publicly available portal about Croatian scientists in Croatia and abroad developed by the Ruđer Bošković Institute (RBI) (Who is who in the Croatian Science). Through the Register of the Researchers all active researchers working in Croatia are issued by a unique researcher ID, which is often used in other information systems as a scientist's unique identifier. Data are collected through official paper register forms and this information is later manually entered into the databases by the Register administrators. There is a constant need for the researchers' profile updates, but currently these are very complicated and inefficient. Therefore, not all of the information in the Register of Researchers is reliable, up-to-date and usable for a CRIS system.

The portal Who is Who in the Croatian Science (URL: http://tkojetko.irb.hr/en/) has been publicly available and intended for a personal promotion of scientists and their contacts with other scientists, entrepreneurs, media and general public. A person's profile in Who is Who database consists of basic personal information and detailed metadata descriptions of researcher education, employment, project activities, memberships, awards, a link to the list of publications in the Croatian Scientific Bibliography - CROSBI, etc. Therefore, it is more detailed and better structured than metadata description in the Registry of Researchers. As a unique identifier it also uses MSE's researcher ID and it doesn't allow input to those not registered in the MSE's Register of the Researchers. The initial input of new record and basic personal information is done by the administrators. Each researcher is then provided with username and password and is responsible for all further editing of his/her profile. Administration of the database is centralized, but there is currently no administration control over the information about researchers entered into the database. The Who is Who portal contains more than 6300 public profiles of the Croatian scientists ${ }^{4}$, but many of them are incomplete and not up-to-date. The reasons

3 Forms are available at URL: https://narodne-novine.nn.hr/clanci/sluzbeni/2004_06_72_1476.html (accessed 20 September 2018)

${ }^{4}$ Source of data: URL: http://tkojetko.irb.hr/en/ (accesses 21 September 2018) 
are likely to be sought in the rising of the scientific social networking, the obsolescence of the portal and its functionalities, as well as in the lacking of institutional support for the usage of the portal on the institutional and/or national level. Since there is no administration control over the information entered into the database, the usage of those data in the future CRIS system is limited and it should be left to individual researchers to decide on the reuse of their data.

\subsection{Databases about projects}

Database of the project activities in the Croatian science and higher education (URL: https://pdb.irb.hr/) is the newest part of the existing Croatian current research infrastructure. It was developed in 2017 by the RBI with the goal to uniquely identify projects by Croatian researchers and institutions, as well as for linking projects with their publication records in various information systems (such as national bibliography CROSBI or Croatian institutional digital repositories). Additionally, project records can be linked with institutions and persons, and potentially with other entities such as scientific equipment. Database currently stores basic information about more than 3500 research projects, as well as about partner institutions and Croatian researchers involved with these projects. The majority of the records were imported by the system administrators from the lists of projects of the major funders, such as EC, MSE and CSF. All registered users may manually enter new records about their projects via a web interface. Records entered by the registered users are visible after database administrators' approval (institutional database administrators or super administrator). The database of project activities serves to the European OpenAIRE portal as an authority source for projects founded by the Croatian funders.

Currently there is only 19 Croatian public institutions with institutional administration accounts. However, since ASHE has adopted this database as a possible source of data for the process of reaccreditation of the Croatian HEIs, it is very likely that other HEIs will also use this database in the near future.

These already collected data about projects could be reused in the future Croatian CRIS system. However, the database itself and its functionalities should be further developed and expanded to store all project activities.

\subsection{Databases about publications}

The infrastructure for storing information about publications is the most developed part of the potential research information system in Croatia. The main part is the Croatian Scientific Bibliography - CROSBI, a national online bibliography which aims to collect bibliographic records of all publications written/edited/mentored by the Croatian scientists, but there are also a number of records archived in the institutional digital repositories hosted by the institutions themselves or by the centrally implemented platform called Digital Academic Archives and Repositories (DABAR).

CROSBI (URL: https://www.bib.irb.hr/) was developed by the RBI in 1997. Initially it was financed by the MSE, after which the RBI continued its maintenance 
and development independently and offered it as a service free of charge to the whole Croatian academic and research community. The general idea of the project was that metadata description of publications should be entered only once, and then it can be exchanged and used for various purposes. Additionally, since its very beginning CROSBI had an option for archiving openly accessible full-texts linked to the bibliographic record [24] as well as saving direct link to the full-text file available in open access anywhere on the Internet. In September 2018 CROSBI had more than 574.000 bibliographic records.

CROSBI enables archiving of any type of publications, such as journal articles, conference proceeding papers or other conference items, books, textbooksf, scripts, book chapters, thesis and dissertations, patents and other type of works. It uses its own rich, extensive and granular metadata description for publications, which could be easily mapped to any metadata standard if needed (e.g., MODS, MARC21, CERIF, Dublin Core etc.). CROSBI also collects bibliometric data, such as journal indexing data, citation counts as well as altmetric data. These data enable potential usage of CROSBI for evaluation of any scientific activity on the individual, institutional and/or national level.

Figuratively, CROSBI is a kind of mini CRIS system because it contains data about publications as well as its relations with the authority lists of researchers/authors, scientific organizations, projects and the scientific fields according to the Croatian classification of science. This enables reporting on research productivity on a personal, institutional or a project level as well as on productivity in a certain scientific field. The authority lists of scientific organizations and researchers have been periodically updated by manual import from MSE's Register of Scientific Organizations, Register of Higher Education Institutions and Register of Researchers. Since the beginning of 2018 the interoperability with MSE's Register of Researchers was implemented so the update of information about researchers is now automated and it is done on a weekly basis. The authority file of projects was created in the CROSBI database to enable linking publication records with MSE projects and creating reports on scientific productivity of MSE projects, and this function was later expanded for CSF and EU projects as well.

For the data ingestion CROSBI is based on self-archiving of new records by authors themselves after their authentication and authorization. It enables manual entry of new records, as well as import from external sources (e.g. CrossRef, Web of Science, RBI's institutional repository - FULIR or the national open access Portal of Scientific Journals of Croatia - Hrčak). New records are instantly publicly visible without the need of prior validation from the database administration side.

Until the end of 2017, the administration of records in CROSBI was centralized and this was one of the CROSBI's weakest points. At the end of 2017 through the support from the ASHE, the third level of administration in CROSBI (institutional administrators) was enabled so now there are:

- database and application administrators - maintain the database and application, including all controlled vocabularies and authority files 
- $\quad$ super administrators - perform the global administration of all records in CROSBI and have authorities to edit/delete any publication record in CORSBI

- institutional administrators - responsible for the accuracy and completeness of all bibliographic records linked to their institution; can edit existing records, but don't have authorities to delete any record.

At the end of September 2018, 32 Croatian public research institutions have had at least one trained institutional administrator of the CROSBI database. However, it will take some time to open accounts and educate all future administrators at Croatian public institutions.

Considering that the third level administration started just recently and that not all CROSBI records are verified, CROSBI still has problems with reliability of some records, their completeness and potential usage for the evaluation purposes. However, the administration of CROSBI data on the institutional level is the right way to deal with these issues.

CROSBI is the most commonly used for reporting on the personal level because the new criteria for scientific promotion prescribe that all candidates must archive their publications metadata into CROSBI [25]. CROSBI was/is also used for reporting on the project output and project leader evaluations performed by the CSF and as a possible tool for Croatian HEIs scientific production reporting in the ASHEs process of reaccreditation of HEIs [26]. These initiatives will also help increasing the level of completeness and authenticity of CROSBI records.

Until recently, the awareness of the need for OA digital repositories among Croatian R\&HE institutions was rather low and their implementation and maintenance was a big technical challenge. Therefore, a development of a common national digital repository infrastructure was initiated. This resulted in establishing of Digital Academic Archives and Repositories - DABAR (URL: https://dabar.srce.hr), a centrally implemented technological solution based on open source software called Islandora that provides Croatian research and higher education institutions with the free, reliable and interoperable digital repository infrastructure [27]. The DABAR infrastructure was developed through a collaboration of five partner institutions with contribution from other Croatian research and higher education institutions and individuals involved in various working groups and a DABAR coordination board [28].

DABAR was released in August 2015 and currently supports archiving of thesis and dissertations, journal articles, proceeding papers, book chapters, art audio and image thesis and conference items. Currently there are 123 open digital repositories on the DABAR infrastructure, majority of which are institutional repositories $(95 \%)$. Approximately $13 \%$ of all opened repositories are still not active (less than 10 archived publications), and only $44 \%$ of them have more than $50 \%$ archived papers available in OA.

Since CROSBI contains more than half a million bibliographic records with a very good quality metadata description, a rich bibliometric data layer, numerous functionalities and a long tradition of use among Croatian researchers, it is a logical choice to be used as a central national database about publications. Although CROSBI 
has some repository functionalities, those functionalities are better developed on the DABAR infrastructure so DABAR would be a plausible choice for publication fulltext archiving, while publications without their institutional repository could be archived on CROSBI or on an orphan repository which could be opened on DABAR. The better interoperability between CROSBI and DABAR should be developed so the publication record should be entered only once, and it could appear in all systems where applicable (in CROSBI and all related institutional repositories).

\subsection{Databases about scientific equipment}

Šestar (in Engl. pair of compasses) (URL: https://sestar.irb.hr/), a database collecting data on equipment for scientific research was developed in 2006 by the RBI. Its development was initially funded by the MSE, after which the RBI continued to develop and maintain it independently. The main goal of Šestar is to improve the use of the available scientific instruments encouraging cooperation between researchers and their organizations, as well as the cooperation between researchers and industry. The records entry is based on self-archiving by the researchers responsible for certain scientific instrument, who can also later update the record. Administrators at the institutional level can update all the records affiliated to the institution, while the super administrators can edit/delete any record and maintain controlled vocabularies.

Until the 2018, Šestar was used mainly at the RBI to keep records on capital equipment located at the RBI, although it was available free of charge to all Croatian public research and higher education institutions. At the beginning of the 2018 the Minister of Science and Education has issued a direction to all Croatian public institutes and universities to archive in Šestar data on their research equipment whose replacement value is greater than approx. 53.000 Euros [29]. As a result, currently there are 40 Croatian institutions using Šestar (institutions which have their institutional administrators) and more than 1400 research instruments recorded in Šestar $^{5}$. Though currently not connected with other parts of the existing information infrastructure, Šestar is flexible for future modifications and integration into the future Croatian CRIS system.

\section{Croatian Current Research Information System (CroRIS) model ${ }^{6}$}

According to the Croatian Strategy of Education, Science and Technology, one of the measures for improving Croatian information and communication infrastructure is to consolidate the existing databases in the higher education domain, connect them with databases in the science and lifelong learning domains and collect all the information needed for evidence-based conclusions [30]. The document Smart Specialization Strategy of the Republic of Croatia for the period from 2016 to 2020 and the Action plan for its implementation in the period from 2016 to 2017 emphasize the need for

\footnotetext{
5 Source of data: URL: https://sestar.irb.hr/en/ (accessed 20 September 2018)

${ }^{6}$ The full CroRIS model was developed as part of doctoral thesis of the first author and this paper only outlines its general idea.
} 
improvement of the national innovation system. The document mentions a strategic project called Scientific and Technological Foresight which should enable a systematic analysis of scientific and technological potentials in Croatia with the goal to improve the institutional framework for research, development and innovation policy [31]. The project is co-financed by the European Regional Development Fund and it started at the end of 2017. The project has been coordinated by the MSE and University of Zagreb, University Computing Centre - SRCE, as a partner institution in charge for developing research information system which will collect all relevant information about Croatian scientific activity needed for science and technology mapping [32].

CroRIS is based on the CERIF data model and it consists of six databases which contain data about scientific organizations, persons involved in research activities in Croatia, projects, publications, scientific equipment and events [33] (Figure 2).

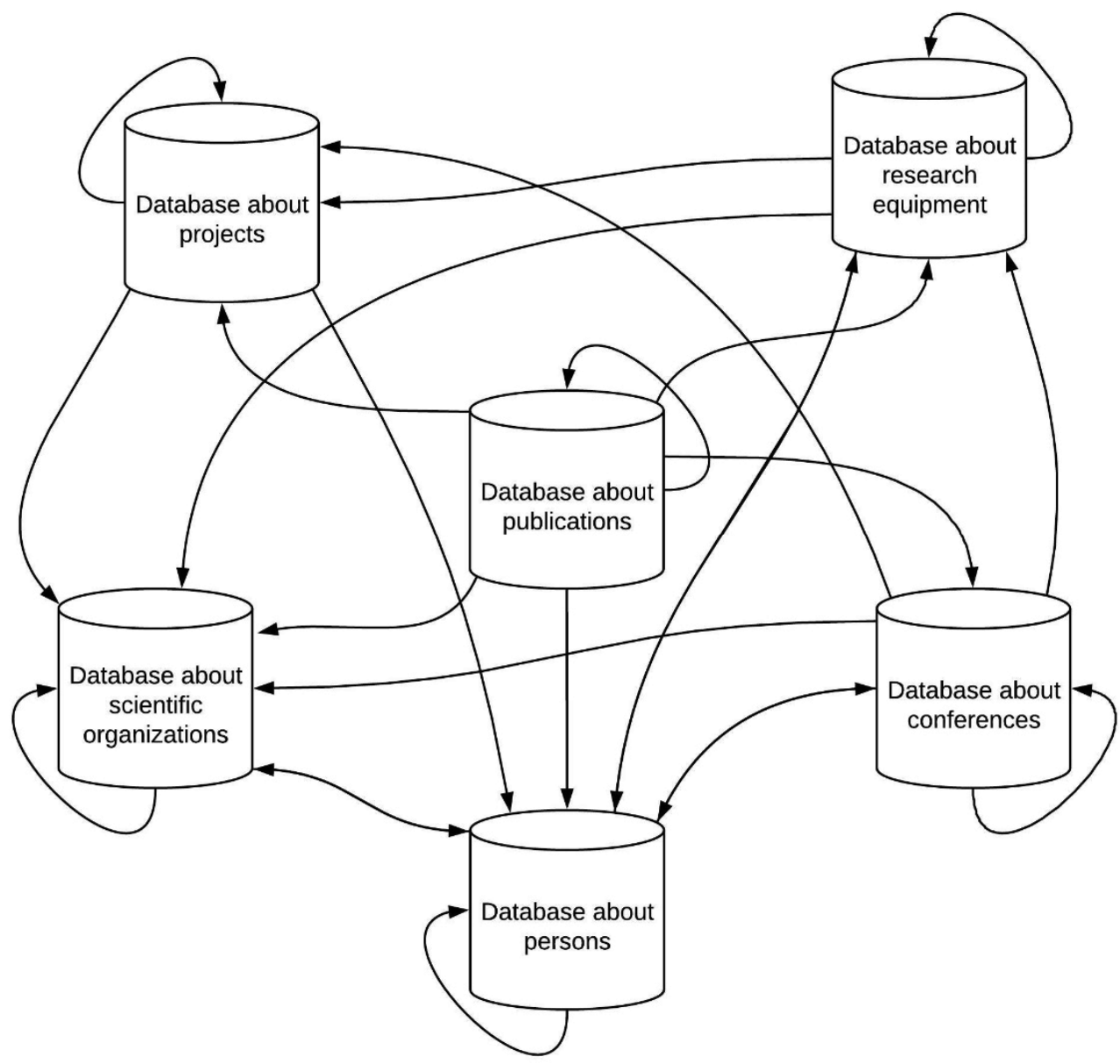

Figure 2. Databases included in CroRIS model and connections between their entities 
Database about scientific organizations should incorporate functionalities of the existing MSE Register of Scientific Organization and Register of Higher Education Institutions, but it should also enable identification of institutional subdivisions for the purpose of later reporting. Considering that departmental organization of the institution is prone to constant changes, a temporal relationship which is one of the CERIF advantages is here very important. The data collection and update should be done via the web interface where institutions should have administration privileges to update their basic information, while the MSE should have administration privileges related to the register functionalities.

Database about persons should have a mixed functionality of the existing Register of Researchers and Who is Who database. This database should also have a wider scope than those two databases and uniquely identify all persons involved in research activities in Croatia (not only researchers). Therefore, the current researcher registration number used as a unique identifier of scientists in Croatia, should be replaced by a more comprehensive identifier in the database about persons (possibly incremental numeric identifier), and all other author or person identifiers (eg., Personal Identification Number (OIB), ORCID, ResearcherID etc.) should be assigned to a person's profile. Data collection should be supported by a user interface, and administered partly by the institutional administrator, partly by the MSE administrator, and partly by persons themselves. This database should also enable a creation of public profiles and each individual could decide about the visibility of all or some metadata.

A central Croatian database about research projects should contain information on all projects on which Croatian researchers and/or Croatian research institutions are collaborating, as well as project proposals submitted by the researchers/institutions. Information about projects would be publicly available, while information about project proposals could be public or visible only to the institutional administrator for the purpose of records keeping and various reporting.

The national research equipment database would contain records about scientific instruments and other research equipment available in the country. The main role of this database is to help researchers locate the available research equipment in the country.

The biggest part of the proposed CroRIS model is a database about publications with included repository functionalities. This database would serve as:

- a Croatian national scientific bibliographic database

- a centrally implemented technological solutions for setting and maintaining digital repositories for all Croatian public research and higher education institutions

- $\quad$ an orphan repository for Croatian authors without affiliation

- a tool for providing additional bibliometric and altmetric indicators for publications relevant for evaluation procedures

- $\quad$ an infrastructure for a long-term preservation of archived digital objects.

The database about publication should allow archiving both, bibliographic data and full-texts of all types of publications. This could be achieved by archiving fulltexts to the database directly or by increasing interoperability with existing digital 
repository infrastructure in Croatia. The current Croatian practice in research assessment regime employs very detailed publication vocabulary as well as performance indicators which are not supported by the CERIF data model. These layers should have to be developed outside the CERIF data model.

A database about conferences has be planned to contain basic metadata description of every conference or workshop organized by or held at any Croatian research or higher education institution as well as the conferences/workshops in which Croatian researchers participated. This is especially important for collecting records about conference papers and presentations in database about publication. In this way, CroRIS system can collect information and generate various reports about conferences organizations, participations and presentations by the Croatian researchers and organizations.

\section{Future perspectives of research information system in Croatia}

Although Croatia currently doesn't have a functional CRIS system, the existing databases cover almost all the main entities which the CRIS systems usually contain. However, these databases are mainly not interconnected and interoperable, in some cases they should be upgraded and modified, and some of the entities should be better described. The biggest disadvantage of the existing research information infrastructure is the lack of the mandatory administration procedures and national legislation support, which results in a questionable reliability of some data. Nevertheless, this is not an insuperable obstacle and a part of the existing infrastructure as well as the majority of archived data could be reused for the development of the fully functional CroRIS system.

Some parts (and initial data) of that future CroRIS system should be built from scratches (database about scientific conferences) while development of the others could be based on previous experiences with similar databases, including appropriate improvements and enhancements. A portion of the existing data could be reused (database about scientists and institutions). A few databases could be upgraded and integrated into the CroRIS system with minor or major modifications (databases about projects, equipment and publications) and the data they contain could be reused. The most developed part of current Croatian research infrastructure are databases about publications (CROSBI, DABAR and other institutional repositories), but they should also be modified and enhanced. The central part of the publication database in CroRIS should be CROSBI which already has a very good quality metadata description (could be mapped into CERIF format), rich bibliometric data layer, well developed functionalities, more than half a million bibliographic records and the 20-year-old tradition of researchers self-archiving. Better interoperability between CROSBI and Croatian digital repositories infrastructure (DABAR) should be developed to avoid multiple publication record entries and to link bibliographic records with available full-texts in open access through repository infrastructure. The data from existing databases should be reused and interlinked, but additional verification on the institutional level is needed before using them for the evaluation purposes. 
The maintenance and further development of future CroRIS system could be done through partnership of relevant institutions, but the administration of the records and the responsibility for the accuracy of the information should be transferred to the administrators/editors at the institutions to which publications/persons/projects/scientific instruments are affiliated. For the quality assurance reasons, the certain level of coordination of institutional administrators is needed. Additionally, the appropriate legislation should be adopted on the national level which should ensure the completeness and reliability of data.

\section{Conclusions}

The current state of information infrastructure in Croatia is not satisfactory, especially in supporting research evaluation. A number of databases which contain data about specific segments of the Croatian research activities already exist, but they are not interconnected and interoperable. However, some of these databases could be used as a basis for a future CroRIS system. The data stored in current databases are occasionally not complete or up-to-date, there are probably some reliability issues, but they are still very valuable and reusable for future needs. The current lack of legislation, financial and organizational support to the infrastructure from all the relevant bodies and policy makers is however the biggest obstacle to implement a functional CRIS system in Croatia.

However, the new MSE project co-financed by the European Regional Development Fund have the unique opportunity to use the good parts of the existing Croatian research information infrastructure, improve them and enrich with the missing parts, as well as create the preconditions for the successful data collecting and curating which would allow a quality decision- and policymaking in the Croatian science.

\section{References}

[1] S. Biesenbender and S. Hornbostel, "The Research Core Dataset for the German science system: developing standards for an integrated management of research information," Scientometrics, vol. 108, no. 1, pp. 401-412, Jul. 2016.

[2] M. Nabavi, K. Jeffery, and H. R. Jamali, "Added value in the context of research information systems," Program: electronic library and information systems, vol. 50, no. 3, pp. 325-339, Jul. 2016.

[3] F. Demšar and T. Boh, "Information systems as tools for managing research activities - how it works at the Slovenian Research Agency," in CRIS 2008: Get the good CRIS going - ensuring quality of service for the zser in the ERA - 9th International Conference on Current Research Information Systems, 2008, pp. 9-19.

[4] S. Biesenbender, S. Petersohn, and C. Thiedig, "Using Current Research 
Information Systems (CRIS) to showcase national and institutional research (potential): research information in the context of open science and university marketing," in CRIS2018: 14th International Conference on Current Research Information Systems (Umeä, June 13-16, 2018), 2018. [Online]. Available: http://hdl.handle.net/11366/653 [Accessed Sept. 21, 2018].

[5] J. Lažnjak and J. Švarc, "Policy-making on science in society between Europeanization and core-periphery divide," Innovation: The European Journal of Social Science Research, vol. 29, no. 1, pp. 98-112, Jan. 2016.

[6] T. Bartol, G. Budimir, D. Dekleva-Smrekar, M. Pušnik, and P. Južnič, "Assessment of research fields in Scopus and Web of Science in the view of national research evaluation in Slovenia," Scientometrics, vol. 98, no. 2, pp. 1491-1504, Feb. 2014.

[7] F. Demšar and P. Južnič, "Transparency of research policy and the role of librarians," Journal of Librarianship and Information Science, vol. 46, no. 2, pp. 139-147, Sep. 2013.

[8] K. Taškova, D. Stojanova, M. Bohanec, and S. Džeroski, “A qualitative decision-support model for evaluating researchers," Informatica, vol. 31, no. 4, pp. 479-486, 2007. [Online serial]. Available:

http://www.informatica.si/index.php/informatica/article/view/171 [Accessed Oct. 15, 2018]

[9] Z. Danica, "The assessment of competence to perform research and development by the SK CRIS: research organisation as an object of evaluation," Procedia Computer Science, vol. 106, pp. 196-203, 2017. [Online serial]. Available:

https://www.sciencedirect.com/science/article/pii/S1877050917302843 [Accessed Sept. 20, 2018]

[10] ISO/TC 46/SC 11 Technical Committee, Ed., ISO 15489-1:2016: Information and documentation : Records management : Part 1: Concepts and principles. International Organization for Standardization, 2016.

[11] B. Macan, "Repozitoriji u otvorenom pristupu: interoperabilnost kao jedini put," in Slobodan pristup informacijama : 13. i 14. okrugli stol : zbornik radova, 2015, pp. 56-71. [Online]. Available: http://fulir.irb.hr/1687/ [Accessed Sept. 25, 2018]

[12] D. Ivanovic, D. Surla, and Z. Konjovic, "CERIF compatible data model based on MARC 21 format," Electronic Library, vol. 29, no. 1, pp. 52-70, Feb. 2011.

[13] "Commission Recommendation of 6 May 1991 concerning the harmonization within the Community of research and technological development databases," Official Journal of the European Union, vol. 34, 
no. L189, 1991. [Online serial]. Available: https:/eur-lex.europa.eu/legalcontent/EN/TXT/?uri=uriserv:OJ.L_.1991.189.01.0001.01.ENG\&toc=OJ: L:1991:189:TOC [Accessed Sept. 25, 2018]

[14] D. Ivanović, G. Milosavljević, B. Milosavljević, and D. Surla, “A CERIFcompatible research management system based on the MARC 21 format," Program: electronic library and information systems, vol. 44, no. 3, pp. 229-251, Jul. 2010.

[15] B. Jörg, K. Jeffery, G. van Grootel, A. Asserson, J. Dvorak, and et al., "CERIF 1.3 Full Data Model (FDM) Introduction and Specification," 2012. [Online]. Available: http://www.eurocris.org/Uploads/Web pages/CERIF-1.3/Specifications/CERIF1.3_FDM.pdf. [Accessed Aug. 9, 2018].

[16] "Main features of CERIF," euroCRIS : Current Research Information Systems, 2018. [Online]. Available: https://www.eurocris.org/cerif/mainfeatures-cerif. [Accessed Sept. 14, 2018].

[17] C. S. Pinto, C. Simões, and L. Amaral, "CERIF - is the standard helping to improve CRIS?," Procedia Computer Science, vol. 33, pp. 80-85, Jan. 2014. [Online serial]. Available:

https://www.sciencedirect.com/science/article/pii/S1877050914008035 [Accessed Sept. 20, 2018]

[18] D. Ivanović, D. Surla, and M. Racković, “A CERIF data model extension for evaluation and quantitative expression of scientific research results," Scientometrics, vol. 86, no. 1, pp. 155-172, Jan. 2011.

[19] D. Ivanovic, D. Surla, and M. Rackovic, "Journal evaluation based on bibliometric indicators and the CERIF data model," Computer Science and Information Systems, vol. 9, no. 2, pp. 791-811, 2012.

[20] J. Schirrwagen and N. Jahn, "Research in context (in view of recent results from OpenAIRE and from the library perspective)," in Proceedings 2013: Seminar on Providing Access to Grey Literature 2013: 6th year of the seminar was held 23rd October 2013 in the National Library of Technology in Prague, 2013. [Online]. Available:

http://invenio.nusl.cz/record/161464/files/idr-685_1.pdf [Accessed Sept. 20, 2018]

[21] "R\&D expenditure in the EU remained stable in 2016 at just over $2 \%$ of GDP," Eurostat - News releases, 2017. [Online]. Available:

http://ec.europa.eu/eurostat/documents/2995521/8493770/9-01122017-APEN.pdf/94cc03d5-693b-4c1d-b5ca-8d32703591e7. [Accessed Sept. 9, 2018].

[22] Croatian Parliament, "The scientific activity and higher education act," Narodne novine, vol. 2003, no. 123, p. 1742, 2003. [Online]. Available: https://narodne-novine.nn.hr/clanci/sluzbeni/2003_07_123_1742.html 
[Accessed Sept. 9, 2018].

[23] Croatian Ministry of Science Education and Sports, "Regulations on Register of scientific organizations and the Register of higher education institutions," Narodne novine, vol. 2004, no. 72, p. 1476, Jan. 2004.

[Online]. Available: https://narodne-

novine.nn.hr/clanci/sluzbeni/2004_06_72_1476.html [Accessed Sept. 9, 2018].

[24] J. Stojanovski, "CROSBI - a tool for monitoring scientific productivity," in TERENA Networking Conference and CARNet User's Conference 2003 Conference Proceedings, 2003.

[25] National Council for Science Higher Education and Technological Development, "Regulations for scientific advancement," Narodne novine, vol. 2017, no. 28, p. 652, 2017. [Online]. Available: https://narodnenovine.nn.hr/clanci/sluzbeni/2017_03_28_652.html [Accessed Sept. 10, 2018].

[26] L. Sīle et al., "Comprehensiveness of national bibliographic databases for social sciences and humanities: Findings from a European survey," Research Evaluation, vol. 27, no. 4, pp. 310-322, Oct. 2018.

[27] D. Celjak, Z. Bekić, M. Cundeković, L. Jertec, M. Milinović, and A. Zubić, "DABAR - the national infrastructure for digital repositories," in EUNIS 23rd annual congress: Shaping the digital future of universities: Book of proceedings, 2017, pp. 16-24. [Online]. Available: https://repozitorij.srce.unizg.hr/islandora/object/srce\%3A61 [Accessed Sept. 22, 2018]

[28] "Digital Academic Archives and Repositories: partner institutions," Digital Academic Archives and Repositories, 2018. [Online]. Available: https://dabar.srce.hr/en/partner-institutions. [Accessed: Oct. 01, 2018].

[29] B. Divjak, "Uputa o evidentiranju i ažuriranju podataka o opremi za znanstvena istraživanja u bazi podataka Šestar." Ministarstvo znanosti i obrazovanja Republike Hrvatske, Zagreb, 2018.

[30] Croatian Parliament, "Strategy of education, science and technology," Narodne novine, vol. 2014, no. 124, p. 2364, 2014. [Online]. Available: https://mzo.hr/sites/default/files/dokumenti/Strategija_OZT/Strategy_eng/s trategy_for_education_science_and_technology.pdf [Accessed Sept. 9, 2018].

[31] "Smart specialization strategy for Croatia from 2016 to 2020 and Action plan for implementation of Smart specialization strategy from 2016-2017," Narodne novine, vol. 2016, no. 32, pp. 2-127, 2016. [Online]. Available: https://narodne-novine.nn.hr/clanci/sluzbeni/dodatni/439965.pdf [Accessed Sept. 9, 2018]. 
[32] B. Matijašević, "Najesen započenje izgradnja CroRIS-a - novog informacijskog sustava o znanstvenoj djelatnosti," Srce novosti., no. 69, pp. 2-3, 2017. [Online]. Available: http://www.srce.unizg.hr/files/srce/docs/osrcu/Srce-novosti/srce_novosti_-_broj_69_-_web.pdf [Accessed Sept 10, 2018].

[33] B. Macan, "Croatian current research information system (CRIS) model," University of Zagreb, Faculty of Humanities and Social Sciences, 2015. [Online]. Available: http://fulir.irb.hr/2075/ [Accessed Oct 18, 2018]. 